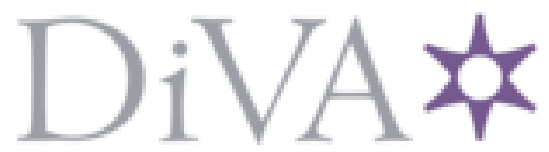

http://www.diva-portal.org

This is the published version of a paper published in RSC Advances.

Citation for the original published paper (version of record):

Bermejo Gómez, A., Holmberg, P., Bäckvall, J-E., Martin-Matute, B. (2014)

Transition metal-catalyzed redox isomerization of codeine and morphine in water.

RSC Advances, 4(74): 39519-39522

https://doi.org/10.1039/c4ra07735k

Access to the published version may require subscription.

N.B. When citing this work, cite the original published paper.

Reprinted with permission from RSC Advances, 2014, 4 (74), 39519-39522. Copyright 2014 The Royal Society of Chemistry.

Permanent link to this version:

http://urn.kb.se/resolve?urn=urn:nbn:se:su:diva- 108400 


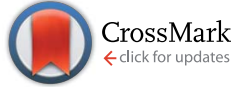

Cite this: RSC Adv., 2014, 4, 39519

Received 28th July 2014

Accepted 6th August 2014

DOI: $10.1039 / \mathrm{c} 4 \mathrm{ra0} 7735 \mathrm{k}$

www.rsc.org/advances

\section{Transition metal-catalyzed redox isomerization of codeine and morphine in water}

\author{
Antonio Bermejo Gómez, ț ${ }^{\text {ab }}$ Pär Holmberg, $\mathfrak{t}^{c}$ Jan-E. Bäckvallțt ab and Belén Martín- \\ Matute ${ }^{* a b}$
}

A water-soluble rhodium complex formed from commercially available $\left[\mathrm{Rh}(\mathrm{COD})\left(\mathrm{CH}_{3} \mathrm{CN}\right)_{2}\right] \mathrm{BF} \mathrm{F}_{4}$ and $1,3,5$ triaza-7-phosphaadamantane (PTA) catalyzes the isomerization of both codeine and morphine into hydrocodone and hydromorphone with very high efficiency. The reaction is performed in water, allowing isolation of the final products by simple filtration, which results in very high isolated yields. The reactions can be easily scaled up to $100 \mathrm{~g}$.
Opium and its derivatives have been used throughout history for medicinal and social purposes. Hydrocodone and hydromorphone are common semi-synthetic opiate drugs used in the treatment of different diseases as, for example, analgesics, antitussives, and sedatives. ${ }^{1}$ Their use has increased in recent years, ${ }^{2}$ as they have superior therapeutic and pharmacokinetic effects compared to codeine and morphine, and are less likely to cause physical dependence. The natural alkaloids codeine (1) and morphine (2) can be transformed into hydrocodone (3) and hydromorphone (4) in a two-step sequence: transition metalcatalyzed hydrogenation followed by Oppenauer oxidation using ${ }^{t} \mathrm{BuOK}$ and benzophenone (Scheme 1). ${ }^{3,4}$ This synthesis

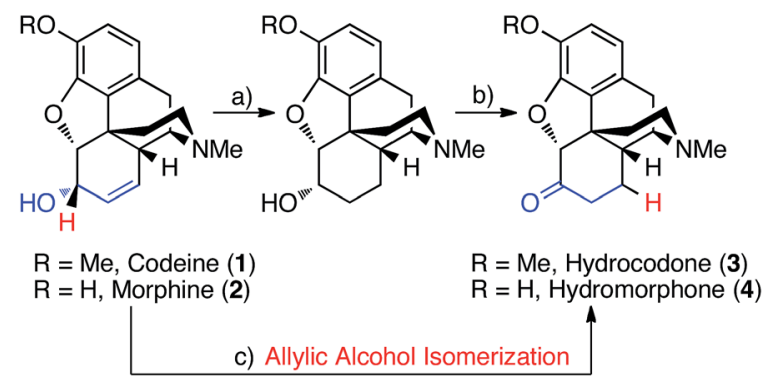

Scheme 1 Synthesis of hydrocodone and hydromorphone. (a) Transition metal-catalyzed hydrogenation; (b) Oppenauer oxidation; (c) redox isomerization. ${ }^{5,6}$

\footnotetext{
${ }^{a}$ Department of Organic Chemistry, Arrhenius Laboratory, Stockholm University, SE-106 91, Stockholm, Sweden. E-mail: belen@organ.su.se; Fax: +468154908 ${ }^{b}$ Berzelii Center EXSELENT, Arrhenius Laboratory, Stockholm University, Stockholm, SE-106 91, Sweden. Fax: +468154908

'Cambrex Karlskoga AB, SE-691 85, Karlskoga, Sweden. E-mail: par.holmberg@ cambrex.com; Fax: +46586783129

$\dagger$ Electronic supplementary information (ESI) available: Experimental procedures and characterisation data of compounds. See DOI: $10.1039 / \mathrm{c} 4 \mathrm{ra} 07735 \mathrm{k}$

\$ The authors declare the following competing financial interest(s): Cambrex has filled patents on the procedures described in this paper (UK1313211.3).
}

route uses oxidants in stoichiometric amounts, and consequently requires tedious purifications, which diminishes the yields. A more efficient alternative to achieve these transformations is the transition metal-catalyzed redox isomerization of the allylic alcohol moieties (Scheme 1, path c). ${ }^{5,6}$ This method yields the products in a single synthetic step through a formal 1,3-hydrogen shift. ${ }^{5-7}$ Great advances have been made in this area of research in the past decade using simple substrates. $^{8-10}$ Applying the transition metal-catalyzed redox isomerization reaction to synthesize semi-synthetic opiate drugs requires overcoming important challenges., ${ }^{5,6}$ For example, the presence of several functional groups in these molecules (e.g., $-\mathrm{OH}, \mathrm{R}^{1}-\mathrm{O}-\mathrm{R}^{2},-\mathrm{NR}_{3}$ ) may hinder the activity of the metal complex, and in general, the isomerization of cyclic allylic alcohols is more difficult than that of acyclic ones. Some pioneering examples on the isomerization of codeine and morphine using transition metal complexes ( $\mathrm{Rh}$ and $\mathrm{Ru}$ ) in organic solvents have been reported., ${ }^{5,6}$ Although these reported methods afford the corresponding hydrocodone or hydromorphone in moderate to good yields using catalytic amounts of transition metal complexes (0.3-4 mol\%), they require the use of dried organic solvents such as toluene, $\mathrm{MeOH}$ or $\mathrm{CH}_{2} \mathrm{Cl}_{2} \cdot{ }^{6}$ In some instances, the activation of the catalysis using $\mathrm{H}_{2}$ gas or MeONa was needed. ${ }^{6 b-d}$ However, there is no report of the use of this catalytic method (i.e. transition-metal-catalyzed isomerization of the allylic alcohol moiety) in water for the synthesis of hydrocodone and hydromorphone. This would greatly simplify the purification of the final products since organic solvents are not used, and the products can be separated by simple filtration. This would minimize their decomposition during tedious purifications and afford higher isolated yields.

Here we report the redox isomerization of codeine (1) and morphine (2) into hydrocodone (3) and hydromorphone (4), respectively, in water and in excellent yields using a commercially available rhodium complex. Compared with other systems described for the isomerization of codeine and morphine, this 
method displayed many advantages such as cost-effective reactions due to the low catalyst loading used and straightforward product isolation.

In order to get familiar with the reactivity and handling of these opiate compounds in our laboratory, we first investigated the redox isomerization of codeine (1) catalyzed by different readily available transition metal complexes based on ruthenium and rhodium (Table 1) in organic solvents. With $\mathrm{Ru}$ complexes (Table 1, entries 1-6), full conversion to the desired product 3 was only observed when $\mathrm{RuCl}_{2}\left(\mathrm{PPh}_{3}\right)_{3}$ was used in dry toluene in the presence of ${ }^{t} \mathrm{BuOK}$ (Table 1 , entry 2). ${ }^{11}$ $\mathrm{RuCpCl}\left(\mathrm{PPh}_{3}\right)_{2}$ gave a complex mixture of unidentified products (Table 1 , entry 3 ) and $\left[\mathrm{Ru}\left(p \text {-cymene) } \mathrm{Cl}_{2}\right]_{2}\right.$ (Table 1 , entry 4 ) afforded very low conversions. With the aim of being able to run the reaction in water, we turned our attention to the use of $\left[\mathrm{Ru}\left(\eta^{3}: \eta^{3}-\mathrm{C}_{10} \mathrm{H}_{16}\right) \mathrm{Cl}_{2}\right]_{2}$, one of the most active $\mathrm{Ru}$ catalysts described for the redox isomerization of allylic alcohols in water. ${ }^{10 a}$ Unfortunately, the starting material was recovered with or without addition of $\mathrm{Cs}_{2} \mathrm{CO}_{3}$ (Table 1, entries 5 and 6). $\mathrm{RhCl}_{3} \cdot 3 \mathrm{H}_{2} \mathrm{O}$ did not catalyze the isomerization (Table 1, entry 7). However, $\left[\mathrm{Rh}(\mathrm{COD})\left(\mathrm{CH}_{3} \mathrm{CN}\right)_{2}\right] \mathrm{BF}_{4}(5)$ when combined with the water-soluble phosphine 1,3,5-triaza-7-phosphaadamantane (L1, PTA) in $\mathrm{H}_{2} \mathrm{O}$ as the solvent ${ }^{10 b}$ gave $>99 \%$ conversion of the starting codeine into hydrocodone (Table 1, entry 9 vs. entry 8).

Further optimization of the reaction catalyzed by $\left[\mathrm{Rh}(\mathrm{COD})\left(\mathrm{CH}_{3} \mathrm{CN}\right)_{2}\right] \mathrm{BF}_{4}(5)$ and PTA (L1) in $\mathrm{H}_{2} \mathrm{O}$ was carried out (Table 2). An advantage of using water as the reaction medium is that the product precipitates, and it can therefore be easily purified by filtration. Since both starting material (1) and final product (3) are insoluble in $\mathrm{H}_{2} \mathrm{O}$, reactions were run to full

Table 1 Screening of ruthenium and rhodium catalysts ${ }^{a}$
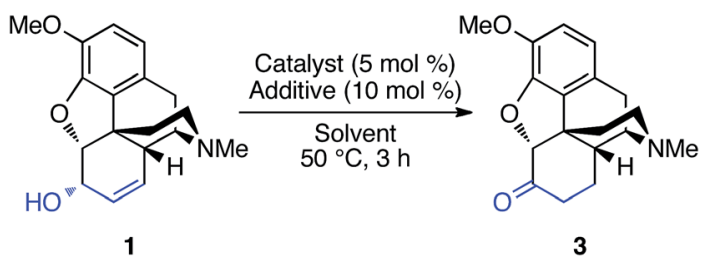

\begin{tabular}{lllll}
\hline Entry & Catalyst & Additive & Solvent & Yield $^{b}(\%)$ \\
\hline 1 & $\mathrm{RuCl}_{3} \cdot x \mathrm{H}_{2} \mathrm{O}$ & ${ }^{t} \mathrm{BuOK}$ & Toluene & $<1$ \\
2 & $\mathrm{RuCl}_{2}\left(\mathrm{PPh}_{3}\right)_{3}$ & ${ }^{t} \mathrm{BuOK}$ & Toluene & $>99$ \\
3 & $\mathrm{RuCpCl}\left(\mathrm{PPh}_{3}\right)_{2}$ & ${ }^{t} \mathrm{BuOK}$ & Toluene & n.d. ${ }^{c}$ \\
4 & {$\left[\mathrm{Ru}(p-c y m e n e) \mathrm{Cl}_{2}\right]_{2}$} & ${ }^{t} \mathrm{BuOK}$ & Toluene & $<1$ \\
5 & {$\left[\mathrm{Ru}\left(\eta^{3}: \eta^{3}-\mathrm{C}_{10} \mathrm{H}_{16}\right) \mathrm{Cl}_{2}\right]_{2}$} & - & $\mathrm{H}_{2} \mathrm{O}$ & $<1$ \\
6 & {$\left[\mathrm{Ru}\left(\eta^{3}: \eta^{3}-\mathrm{C}_{10} \mathrm{H}_{16}\right) \mathrm{Cl}_{2}\right]_{2}$} & $\mathrm{Cs}_{2} \mathrm{CO}_{3}$ & $\mathrm{H}_{2} \mathrm{O}$ & $<1$ \\
7 & $\mathrm{RhCl} \cdot 3 \mathrm{H}_{2} \mathrm{O}$ & ${ }^{t} \mathrm{BuOK}$ & Toluene & $<1$ \\
8 & {$\left[\mathrm{Rh}(\mathrm{COD})\left(\mathrm{CH}_{3} \mathrm{CN}\right)_{2}\right] \mathrm{BF}_{4}(5)$} & - & $\mathrm{H}_{2} \mathrm{O}$ & $<1$ \\
9 & $\mathbf{5}$ & $\mathrm{PTA}$ & $\mathrm{H}_{2} \mathrm{O}$ & $>99$
\end{tabular}

${ }^{a} 1$ ( $\left.0.1 \mathrm{mmol}\right)$, metal complex ( $\left.5 \mathrm{~mol} \%\right)$, and additive $(10 \mathrm{~mol} \%)$ in degassed solvent $(2 \mathrm{~mL})$ at $50{ }^{\circ} \mathrm{C}$, for $3 \mathrm{~h}$ under an atmosphere of $\mathrm{N}_{2}$ in a sealed tube. ${ }^{b}$ Determined by ${ }^{1} \mathrm{H}$ NMR spectroscopy. ${ }^{c} \mathrm{~A}$ complex mixture of by-products was formed. $\mathrm{Cp}=$ cyclopentadienyl; $\mathrm{C}_{10} \mathrm{H}_{16}=$ 2,7-dimethylocta-2,6-diene-1,8-diyl; COD = 1,5-cyclooctadiene; PTA $=$ 1,3,5-triaza-7-phosphaadamantane.
Table 2 Optimization of the reaction conditions using 5 and $\mathrm{L1}^{a}$

\begin{tabular}{|c|c|c|c|c|c|c|}
\hline & $\begin{array}{l}\text { 1, } R=M \\
\text { 2, } R=H\end{array}$ & $\begin{array}{r}\text { [Rh(CO } \\
\text { le } \\
\text { De }\end{array}$ & ssed $\mathrm{H}_{2} \mathrm{O}$ & $\begin{aligned} & \mathrm{RO} \\
= & { }_{4}\end{aligned}$ & $\begin{array}{l}3, R=1 \\
4, R=1\end{array}$ & \\
\hline Entry & Substrate & $5(\mathrm{~mol} \%)$ & $\begin{array}{l}\mathbf{L 1} \\
(\mathrm{mol} \%)\end{array}$ & $\begin{array}{l}t \\
(\mathrm{~h})\end{array}$ & $T\left({ }^{\circ} \mathrm{C}\right)$ & Yield $^{b}(\%)$ \\
\hline 1 & 1 & 5 & 10 & 2 & 80 & 93 \\
\hline 2 & 1 & 1 & 2 & 3 & 80 & 94 \\
\hline 3 & 1 & 0.1 & 0.2 & 12 & 80 & 87 \\
\hline 4 & 1 & 0.1 & 0.2 & 24 & 100 & $>99$ \\
\hline 5 & 1 & 0.05 & 0.1 & 21 & 70 & 30 \\
\hline 6 & 1 & 0.05 & 0.1 & 21 & 100 & 93 \\
\hline 7 & 1 & 0.05 & 0.1 & 24 & $130^{c}$ & 98 \\
\hline 8 & 1 & 0.05 & 0.05 & 20 & 100 & 19 \\
\hline 9 & 2 & 5 & 10 & 2 & 100 & $>99$ \\
\hline 10 & 2 & 1 & 2 & 20 & 100 & $>99$ \\
\hline 11 & 2 & 0.7 & 1.4 & 20 & 100 & $>99$ \\
\hline 12 & 2 & 0.5 & 1 & 21 & 100 & 86 \\
\hline 13 & 2 & 0.1 & 0.2 & 21 & 100 & $<1$ \\
\hline
\end{tabular}

${ }^{a}$ Unless otherwise noted: 1 or $2(1 \mathrm{~g}, 3.34 \mathrm{mmol}$ or $3.50 \mathrm{mmol})$ in degassed $\mathrm{H}_{2} \mathrm{O}(7 \mathrm{~mL})$, under a $\mathrm{N}_{2}$ atmosphere in a sealed tube. ${ }^{b}$ Determined by ${ }^{1} \mathrm{H}$ NMR spectroscopy after isolation by filtration. ${ }^{c}$ At this temperature, $\mathbf{1}$ and $\mathbf{3}$ did not precipitate from the reaction medium.

conversion. All optimization reactions were performed on a one gram scale $(3.34 \mathrm{mmol}$ of $\mathbf{1})$ to ensure reproducibility.

When the catalyst loading was decreased from $5 \mathrm{~mol} \%$ to $1 \mathrm{~mol} \%$ at $80{ }^{\circ} \mathrm{C}$, the activity was not significantly affected (Table 2, entry 1 vs. 2). Lower catalyst loadings ( $0.1 \mathrm{~mol} \%$ ) did not give full conversion, despite prolonged reaction times (Table 2, entry 3). However, when the temperature was increased to $100^{\circ} \mathrm{C}$, full conversion was obtained with a catalyst loading as low as $0.1 \mathrm{~mol} \%$ (Table 2, entry 4). With a further decrease in the Rh loading $(0.05 \mathrm{~mol} \%)$ a high yield of $93 \%$ was obtained at $100{ }^{\circ} \mathrm{C}$ (Table 2 , entry 6), and this could be increased to $98 \%$ by running the reaction at $130{ }^{\circ} \mathrm{C}$ (Table 2, entry 7). However, $130{ }^{\circ} \mathrm{C}$ is less suitable for large-scale applications, and thus $100^{\circ} \mathrm{C}$ was chosen as the optimal temperature. The ratio 5/ L1 was also varied, and it was found that a ratio of $1: 2$ (metal/ phosphine) was needed to obtain excellent yields (Table 2, entry 8 vs. entry 6). Optimization was also performed for the isomerization of morphine (2) (Table 2, entries 9-13). To obtain good results with this substrate (2), the lowest catalyst loading that could be used was $0.7 \mathrm{~mol} \%$ (Table 2, entry 11 vs. 13). The lower reactivity of morphine (2) compared to codeine (1) could be due to the inhibition of the activity of the catalyst through interaction of the metal atom with the phenol moiety.

Sulfonate phosphine sodium salts have been extensively used as water-soluble ligands in transition metal catalysis. ${ }^{12}$ When water-soluble phosphines L2-L4 ${ }^{13}$ (Fig. 1) were used in 


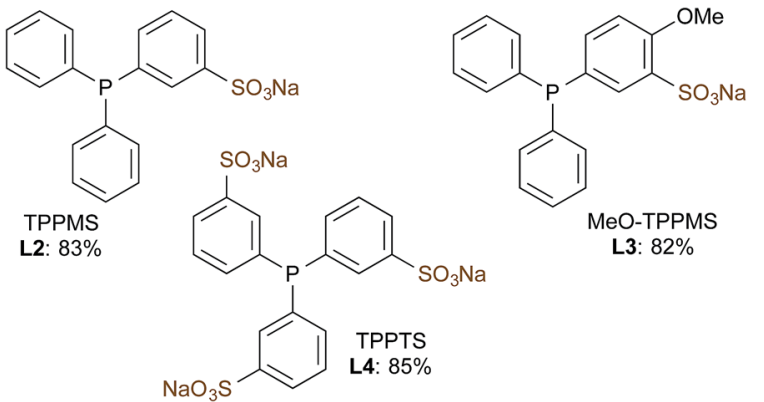

Fig. 1 Yields determined by ${ }^{1} \mathrm{H}$ NMR spectroscopy obtained in the isomerization of 1 catalyzed by 5 and ligands L2-L4 (5, $1 \mathrm{~mol} \%$; L, 2 mol\%, $100{ }^{\circ} \mathrm{C}, 3.5 \mathrm{~h}$ in $\mathrm{H}_{2} \mathrm{O}$ ). TPPMS = sodium (3-sulfonatephenyl)diphenylphosphine; MeO-TPPMS = sodium (4-methoxy-3-sulfonatephenyl)-diphenylphosphine; TPPTS = trisodium tris(3-sulfophenyl) phosphine.

the isomerization of $\mathbf{1}$ catalyzed by 5 , yields ranging from 82 to $85 \%$ were obtained after $3.5 \mathrm{~h}$ at $100{ }^{\circ} \mathrm{C}$ in degassed $\mathrm{H}_{2} \mathrm{O}$ (Fig. 1). However, yields as high as those obtained with PTA (L1) were not achieved. Also, PTA can be easily synthesized in a multigram scale from readily available reagents. ${ }^{\mathbf{1 4}}$

Next, we carried out the redox isomerization of codeine (1) and morphine (2) on a gram scale under the optimal reaction conditions found (Table 2, entries 4 and 11) and determined the isolated yields. The products, 3 and $\mathbf{4}$ respectively, were isolated by filtration in 89 and $77 \%$ yield (Schemes $2 \mathrm{a}$ and $\mathrm{b}$, see $\mathrm{ESI} \dagger$ for details).

To show further the potential of catalytic system $\mathbf{5} / \mathbf{L 1}$, the isomerization of codeine 1 was also performed on a $100 \mathrm{~g}$ scale and using $0.1 \mathrm{~mol} \%$ of 5 (Scheme 3). This procedure gave
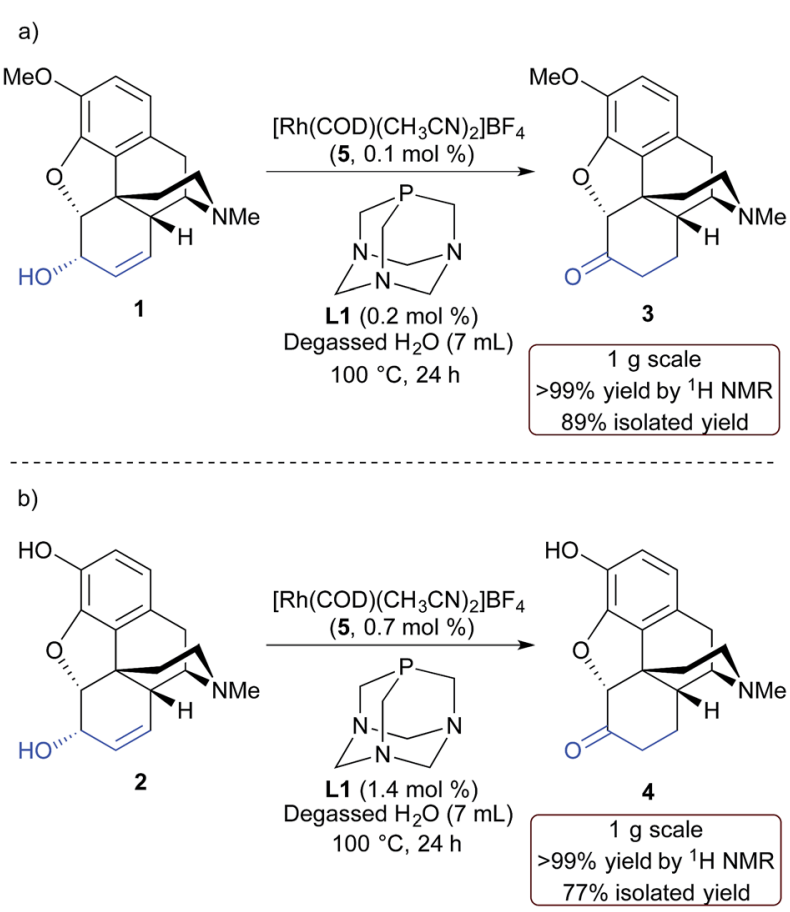

Scheme 2 Synthesis of 3 and 4 .

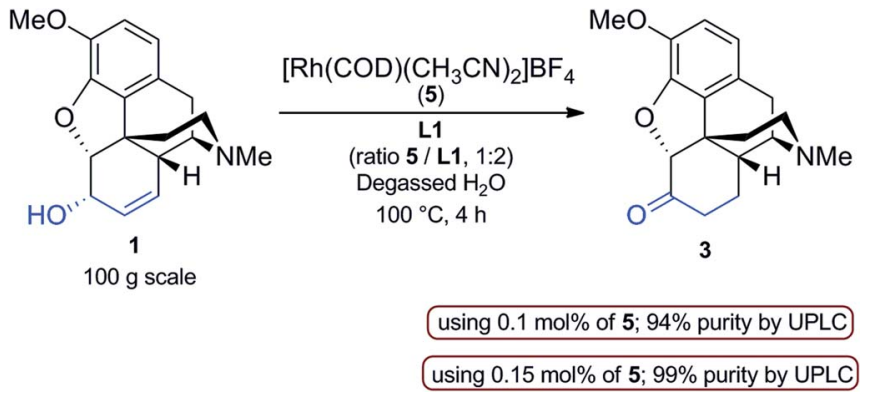

Scheme 3 Synthesis of 3 on a $100 \mathrm{~g}$-scale.

hydrocodone 3 in $90 \%$ isolated yield in only $4 \mathrm{~h}$. The purity of the product was determined by UPLC analysis (see ESI $\dagger$ for details), and it was of $94 \%$. The isolated solid contained $3 \%$ of the starting codeine $\mathbf{1}$. To increase the conversion of the redox isomerization, at this large scale, the same reaction described above was carried out using $0.15 \mathrm{~mol} \%$ of the Rh complex 5 , and the purity of the final isolated product 3 was successfully increased up to $99 \%$ (Scheme 3).

\section{Conclusions}

In conclusion, we have reported an easy, scalable, practical, and high-yielding procedure for the synthesis and isolation of hydrocodone and hydromorphone from codeine and morphine in water. The method is based on the redox isomerization of the corresponding allylic alcohols catalyzed by low loadings of a water soluble complex formed from commercially available $\left[\mathrm{Rh}(\mathrm{COD})\left(\mathrm{CH}_{3} \mathrm{CN}\right)_{2}\right] \mathrm{BF}_{4}$ (5) and 1,3,5-triaza-7-phosphaadamantane (PTA, L1). The reactions were carried out in $\mathrm{H}_{2} \mathrm{O}$, and isolation of the products could be performed by simple filtration, avoiding tedious purifications, and thus minimizing decomposition of the products, resulting in very high isolated yields. Having demonstrated the efficiency of this water-soluble catalytic system for the synthesis of these semi-synthetic opiate drugs in up to $100 \mathrm{~g}$-scale, we believe that the results reported here will be of significant interest for the commercial preparation of these compounds at a much larger scale, which may even allow to further reduce the catalyst loading.

\section{Acknowledgements}

This project was generously supported by Cambrex Karlskoga AB, the Swedish Governmental Agency for Innovation Systems (VINNOVA) through the Berzelii Center EXSELENT, the Swedish Research Council (VR) and the Knut and Alice Wallenberg Foundation. B.M.-M. was supported by VINNOVA through a VINNMER grant.

\section{Notes and references}

1 H. P. Rang, M. M. Dale, J. M. Ritter, R. J. Flower and G. Henderson, Rang \& Dale's pharmacology, Elsevier, 7th edn, 2012. 
2 International Narcotics Control Board (INCB), World's totals of estimates from 2009 to 2014: http://www.incb.org/ documents/Narcotic-Drugs/Technical-Publications/2013/ Annex_2_EFS.pdf, (accessed in March, 2014).

3 (a) R. Csuk, G. Vasileva and A. Barthel, Synthesis, 2012, 44, 2840-2842; (b) T. H. Black, J. C. Forsee and D. A. Probst, Synth. Commun., 2000, 30, 3195-3201.

4 Synthesis of hydrocodone from thebaine: (a) H. Leisch, R. J. Carroll, T. Hudlicky and D. P. Cox, Tetrahedron Lett., 2007, 48, 3979-3981; (b) R. J. Carroll, H. Leisch, L. Rochon, T. Hudlicky and D. P. Cox, J. Org. Chem., 2009, 74, 747-752.

5 Recent review of patents on the redox isomerisation of codeine and morphine: A. E. Díaz-Álvarez and V. Cadierno, Recent Patents Catal., 2012, 1, 43-50.

6 Isomerization of codeine and/or morphine in organic solvents, using $\mathrm{Rh}(\mathrm{I})$ catalysts and $\mathrm{Ru}(\mathrm{II})$ : (a) P. X. Wang and C. R. White, US 7323565 B2, 2008; (b) P. X. Wang, F. W. Moser, G. L. Cantrell, P. Magparangalan and J. Bao, US 20087399858 B2, 2008; Using Rh(I) complexes: (c) V. Kouznetsov, US 20087399859 B1, 2008; (d) B. Mudryk, J. Kant and C. Sapino, US 19985847142, 1998; (e) B. Mudryk, J. Kant and C. Sapino, EP 19970915884 B1, 1997; (f) B. Mudryk, J. Kant and C. Sapino, WO 199805667 A1, 1998; Using Ru black: $(g)$ D. E. Gindelberger, WO 2011035276, 2011; Using Ru(Iv) catalysts: $(h)$ P. X. Wang, T. Jiang and D. W. Berberich, WO 2010118271, 2010; $(i)$ T. Jiang, P. X. Wang and D. W. Berberich, WO 2011137086, 2011; Using $\mathrm{Ru}(\mathrm{III})$ catalysts: (j) P. X. Wang, T. Jiang, D. W. Berberich, N. Gurusamy and C. K. Jung, WO 2010118275, 2010; Using Ru(II) catalysts:

D. E. Gindelberger, WO 2010118273, 2010.

7 N. Ahlsten, A. Bartoszewicz and B. Martín-Matute, Dalton Trans., 2012, 41, 1660-1670.

8 Selected reviews on the isomerization of allylic alcohols: (a) R. C. van der Drift, E. Bouwman and E. Drent, J. Organomet. Chem., 2002, 650, 1-24; (b) R. Uma, C. Crévisy and R. Grée, Chem. Rev., 2003, 103, 27-51; (c) V. Cadierno, P. Crochet and J. Gimeno, Synlett, 2008, 8, 1105-1124; (d) L. Mantilli and C. Mazet, Chem. Lett., 2011, 40, 341-344; (e) P. Lorenzo-Luis, A. Romerosa and M. Serrano-Ruiz, ACS Catal., 2012, 2, 1079-1086.

9 Selected examples on isomerization and tandem reactions: using halogen electrophiles, see: (a) N. Ahlsten and B. Martín-Matute, Chem. Commun., 2011, 47, 8331-8333; (b) N. Ahlsten, A. Bartoszewicz, S. Agrawal and B. MartínMatute, Synthesis, 2011, 16, 2600-2608; (c) N. Ahlsten, A. Bermejo Gómez and B. Martín-Matute, Angew. Chem., 2013, 125, 6393-6396; Angew. Chem., Int. Ed., 2013, 52, 6273-6276; (d) A. Bermejo Gómez, E. Erbing, M. Batuecas, A. Vázquez-Romero and B. Martín-Matute, Chem.-Eur. J., 2014, 20, 10703-10709; Using carbon electrophiles, see: $(e)$
X.-F. Yang, M. Wang, R. S. Varma and C.-J. Li, Org. Lett., 2003, 5, 657; (f) V. Branchadell, C. Crévisy and R. Grée, Chem.-Eur. J., 2004, 10, 5795; (g) D. Cuperly, J. Petrignet, C. Crévisy and R. Grée, Chem.-Eur. J., 2006, 12, 3261; (h) J. Petrignet, I. Prathap, S. Chandrasekhar, J. S. Yadav and R. Grée, Angew. Chem., 2007, 119, 6316; Angew. Chem., Int. Ed., 2007, 46, 6297; (i) A. Bartoszewicz, M. Livendahl and B. Martín-Matute, Chem.-Eur. J., 2008, 14, 10547; (j) N. Ahlsten and B. Martín-Matute, Adv. Synth. Catal., 2009, 351, 2657; $(k)$ A. Mizuno, H. Kusama and N. Iwasawa, Chem.-Eur. J., 2010, 16, 8248; (l) H. T. Cao, T. Roisnel, A. Valleix and R. Grée, Eur. J. Org. Chem., 2011, 3430; (m) L. Lin, K. Yamamoto, S. Matsunaga and M. Kanai, Angew. Chem., 2012, 124, 10421; Angew. Chem., Int. Ed., 2012, 51, 10275; (n) A. Bartoszewicz, M. M. Jeżowska, K. Laymand, J. Möbius and B. Martín-Matute, Eur. J. Inorg. Chem., 2012, 1517-1530.

10 Isomerization of allylic alcohols in water: $(a) \mathrm{V}$. Cadierno, S. E. García-Garrido, J. Gimeno, A. Varela-Álvarez and J. A. Sordo, J. Am. Chem. Soc., 2006, 128, 1360-1370; (b) N. Ahlsten, H. Lundberg and B. Martín-Matute, Green Chem., 2010, 12, 1628-1633; (c) L. Bellarosa, J. Díez, J. Gimeno, A. Lledós, F. J. Suárez, G. Ujaque and C. Vicent, Chem.-Eur. J., 2012, 18, 7749-7765; Isomerization in THF and MeOH: (d) R. Uma, M. K. Davies, C. Crévisy and R. Grée, Eur. J. Org. Chem., 2001, 3141-3146.

$11 \mathrm{RuCl}_{2}\left(\mathrm{PPh}_{3}\right)_{3}$ has been used before in $\mathrm{MeOH}$ as the solvent in the presence of $\mathrm{Et}_{3} \mathrm{~N}$ (see ref. $6 a$ and $b$ ).

12 Selected recent examples: (a) S. Sahoo, H. Lundberg, N. Ahlsten, M. Edén, W. Wan, X. Zou and B. MartínMatute, ChemCatChem, 2012, 4, 243-250; (b) I. Nakamura, M. Okamoto, Y. Sato and M. Terada, Angew. Chem., Int. Ed., 2012, 51, 10816-10819; (c) J. Li, H. Fu, P. Hu, Z. Zhang, X. Li and Y. Cheng, Chem.-Eur. J., 2012, 18, 13941-13944; (d) H. Hikawa, H. Suzuki and I. Azumaya, J. Org. Chem., 2013, 78, 12128-12135; (e) L. T. Mika, L. Orha, E. van Driessche, R. Garton, K. Zih-Perényi and I. T. Horváth, Organometallics, 2013, 32, 5326-5332; $(f)$ P. Nauš, O. Caletková, P. Konečný, P. Džubák, K. Bogdanová, M. Kolář, J. Vrbková, L. Slavětínská, E. Tloušt'ová, P. Perlíková, M. Hajdúch and M. Hocek, J. Med. Chem., 2014, 57, 1097-1110.

13 (a) W. A. Herrmann, G. P. Albanese, R. B. Manetsberger, P. Lappe and H. Bahrmann, Angew. Chem., Int. Ed., 1995, 34, 811-813; (b) H. Gulyás, À. Szöllősy, P. Szabó and J. Bakos, Eur. J. Org. Chem., 2003, 15, 2775-2781; (c) H. Gulyás, Z. Bacsik, À. Szöllősy and J. Bakos, Adv. Synth. Catal., 2006, 348, 1306-1310.

14 D. J. Daigle, T. J. Decuir, J. B. Robertson and D. J. Darensbourg, Inorg. Synth., 1998, 32, 40-45. 